\title{
Research on Decentralized Supply Chain with Channel-Wide Profit Maximization
}

\author{
Liang-Tu Chen ${ }^{1,}$, , Shih-Wen Chien ${ }^{2}$, Chun-Chin $\mathrm{Wei}^{3}$ \\ ${ }^{1}$ Department of Commerce Automation and Management, National Pingtung University, Pingtung, Taiwan ROC \\ ${ }^{2}$ Department of Information Management, National Kaohsiung University of Applied Sciences, Kaohsiung, Taiwan ROC \\ ${ }^{3}$ Department of Marketing and Distribution Management, Chien-Hsin University, Chungli, Taiwan ROC
}

\section{Email address:}

ltchen@mail.nptu.edu.tw (Liang-Tu Chen), swchien@kuas.edu.tw (Shih-Wen Chien),d887801@uch.edu.tw (Chun-Chin Wei)

${ }^{*}$ Corresponding author

\section{To cite this article:}

Liang-Tu Chen, Shih-Wen Chien, Chun-Chin Wei. Research on Decentralized Supply Chain with Channel-Wide Profit Maximization. Science Journal of Business and Management. Vol. 5, No. 4, 2017, pp. 132-135. doi: 10.11648/j.sjbm.20170504.11

Received: April 9, 2017; Accepted: June 6, 2017; Published: June 14, 2017

\begin{abstract}
This study explores the problem of optimally dynamic joint decisions: replenishment quantity, retail price and depletion time, in a vertically decentralized single-retailer and single-supplier supply chain over a dynamic multi-period planning horizon, subject to multivariate demand function and deteriorating goods with shortages allowed and with no consideration of fixed costs. This research uses a calculus-based formulation coupled with dynamic programming techniques to solve the channel-wide profit maximization under price-only contract and consignment contract respectively. The analysis reveals that the consignment contract can significantly achieve higher channel-wide profit than the price-only contract for the dynamic decentralized channel.
\end{abstract}

Keywords: Decentralized Supply Chain, Dynamic Pricing, Shortages, Fixed Costs

\section{Introduction}

The need for inter-company coordination and cooperation between production and marketing planning in a vertically separated supply chain has attracted considerable attention during recent decades. Upstream vendors and downstream buyers can be managed and eliminated through properly designed methods and coordinating mechanisms, including organizational design, quick response, reward system, return policy, quantity discount, consignment, and so on. Comprehensive reviews related to this area of the literature were conducted by [1-6]. Relationships between suppliers and retailers are based on supply chain contracts. These coordinating mechanisms above are frequently designed as supply chain contracts to maximize the channel-wide profit.

If a retailer desires to carry goods in the store without buying it, the solution may use consignment contract. A supplier retains ownership of the goods, and sets the retail price and replenishment quantity for his goods under the consignment arrangement, while the retailer deducts a percentage from the retail price and remits the balance to the supplier for the goods sold [7]. Comprehensive reviews related to consignment contract include [8-9]. The question is whether supply chain contracts can replace the traditional supply chain strategy while optimizing channel performance and, particularly, in practice whether suppliers can apply consignment strategies to offer incentives to retailers to order more goods while simultaneously increasing the profits of channel-wide [10-11]. This study proposes a policy involving a consignment contract is applied to solve the problem of optimally dynamic decisions in a single-retailer and single-supplier supply chain over a multi-period planning horizon for a deteriorating commodity.

As we know, supply chains are dynamic systems that evolve over time. Not only does customer demand change over time, but the supply chain relationship also progresses. Even if demand is known, the planning process still requires considering demand parameters that vary over time, due to the impacts of price, trend, promotion, etc. [12]. In practice, price change is increasingly adopted as a means of controlling demand due to its effectiveness for short-term control over on-hand stock. Pashigian and Bowen [13] demonstrated that 
both percentage markups and frequency of sales for fashion goods have increased since 1970. Comprehensive studies dealing with dynamic pricing and stock problems include [14-17]. This investigation focuses on the problem of joint dynamic decisions under both coordinating policies in a vertically decentralized channel over a multi-period planning horizon. Deterioration applies to considerable inventory items, including volatile liquids, agricultural products, drugs, blood, fashion goods and high-tech products. All of these items are subject to depletion by phenomena other than demand, such as shrinkage, decay, obsolescence, scrap and spoilage. A survey by the National Accounting Association disclosed that unreported scrap is the primary cause of inventory loss regardless of product type or industry [18]. These phenomena of deterioration are prevalent and should not be ignored. Representative studies on related to the deteriorating items include [19-20].

This investigation uses a calculus-based formulation coupled with dynamic programming techniques to solve joint retail price, depletion time and replenishment quantity decision problems under the price-only contract and consignment contract respectively over a multi-period planning setting, comprising multivariate demand function and multiple dynamic replenishment cycles for deteriorating goods with shortages allowed and with no consideration of fixed costs (i.e. replenishment operations cost, production setup cost and slotting allowance cost), thus enhancing system efficiency for a vertically decentralized single-supplier and single-retailer channel.

\section{Problem Description}

To illustrate the importance and impact of different supply chain contracts on channel performance, this research considers a typical two-stage supply chain comprising one supplier and one retailer. This study deals with a single item whose retail price and inventory are reviewed periodically at time $t$. Each period begins with a joint decision regarding the scheduling of a new replenishment and its associated retail price and depletion time. The problem is equivalent to determining the optimal sequence of issuance times for new replenishment with the retail price and depletion time being reset, and the lot-size simultaneously specified so as to maximize the profit stream. This study also assumes the replenishment is instantaneous and no inventory is held at the beginning and at the end of the time horizon. The following notations are used throughout the study.

$h=$ Per unit holding cost for given unit of time.

$s=$ Per unit shortage cost for given unit of time.

$c=$ Per unit production cost.

$w=$ Per unit purchase cost.

$\varphi=$ Constant product perishability rate

$v=$ Fraction of channel revenue retained by retailer.

\section{The Modes}

In the section, this study presents a dynamic version of the channel coordination decisions, including the retail price, depletion time and replenishment quantity under the price-only contract and consignment contract respectively in a vertically decentralized single-supplier and single-retailer channel over a multi-period planning horizon, subject to deteriorating goods and multivariate demand function. That is two alternatives for doing business. One alternative is the price-only contract, where the retailer owns the goods ownership and is entirely responsible to the retail price, depletion time and replenishment quantity decisions. The other alternative is the consignment contract, where the supplier still owns the goods title and is fully responsible to the retail price, depletion time and replenishment quantity decisions in the channel. This study first presents the price-only contract, and then the consignment contract for the decentralized channel coordination.

\subsection{Price-Only Contract}

In a vertically decentralized channel, a customary behavior of channel coordination is operated in such a way that a make-to-order supplier produces the products using a lot-for-lot policy with a unit cost and sells them to market through a coordinating retailer under price-only contract with a purchase price; the retailer decides on the retail price, depletion time and replenishment quantity. The ownership of the products is transferred from the supplier to the retailer when the products are received.

The base model considers a price-only contract in a vertically decentralized two-echelon supply chain with one supplier and one retailer. That is the retailer has the right to decide the replenishment quantity besides the retail price and depletion time, and focuses only on herself profit maximization over the multi-period planning horizon, without considering her counterpart's reaction and channel-wide profit. The retailer owns the goods ownership and holds inventory of the goods which is subject to a constant deteriorating rate, and replenishes inventory from the supplier in order to meet a deterministic price-dependent and time-varying demand. In the section, the study first derives a generic model for determining the optimal joint decisions: retail price, depletion time and lot-size over an arbitrary selling period $\left[z_{j-1}, z_{j}\right]$ and proves the uniqueness of the solutions. The model is further extended into a multi-period formulation where the optimal sequence of replenishments $z_{j-1}$ and associated retail price, depletion time/service level and lot-size for $j=1,2, \ldots, n$, are determined using a dynamic programming approach.

In the periodic review inventory system, the cycle starts with a replenishment at $z_{j-1}$ and inventory is held until time $\xi$ at which the stock is completely depleted, followed by a period of shortages until the next replenishment at $z_{j}$. By considering the joint effect of demand and deterioration over period $[t, \xi], z_{j-1} \leq t \leq \xi$, the inventory level at time $t$ is the following: 


$$
I(p, t)=\int_{t}^{\xi} D(p, u) e^{\int_{t}^{u} \varphi(\tau(v)) d \tau(v)} d u, \quad z_{j-1} \leq t \leq \xi
$$

On the other hand, the shortage level over time period $[\xi, t]$ is:

$$
S(p, t)=\int_{\xi}^{t} D(p, u) d u, \quad \xi \leq t \leq z_{j} .
$$

The retailer profit over an arbitrary selling period $\left[z_{j-1}, z_{j}\right]$ is the retail revenue minus the relevant costs due to the purchasing cost, holding cost, deteriorating cost and shortage cost:

$$
\begin{array}{r}
\pi_{p o, R}(p, \xi)=p \int_{z_{j-1}}^{z_{j}} D(p, t) d t-w \int_{z_{j-1}}^{\xi} D(p, t) e^{\int_{z_{j-1}}^{t} \varphi d u} d t- \\
h \int_{z_{j-1}}^{\xi} \int_{t}^{z_{j}} D(p, u) e^{\int_{t}^{u} \varphi d v} d u d t-\int_{\xi}^{z_{j}}\left(w+s\left(z_{j}-t\right)\right) D(p, t) d t .
\end{array}
$$

The sequence of events in the price-only model is as follows: both companies negotiate a wholesale price $w$ beforehand, based on which the retailer determines the coordinated retail price and depletion time simultaneously over given $z_{j-1}$ and $z_{j}$ for the supply chain. Therefore, the optimal retail price and depletion time that maximizes the retailer profit over period $\left[z_{j-1}, z_{j}\right]$ in the price-only contract can be obtained by taking the first-order derivative of Eqn. (3) with respect to $p$ and $\xi$ separately and setting the results equal to zero. For further extending into a multi-period planning horizon formulation, the study applies the dynamic programming approach to determine the optimal replenishment scheduling, the associated retail price and depletion time, and the profits of the retailer, supplier and channel-wide.

\subsection{Consignment Contract}

In the decentralized channel coordination with consignment contract, the supplier owns the goods title, and decides the sequence of replenishment besides the retail price and depletion time over the multi-period planning horizon, while the retailer deducts a percentage from the retail price and remits the balance to the supplier. Let $v(0 \leq v \leq 1)$ be the fraction of channel revenue the retailer keeps, so $(1-v)$ is the fraction the supplier earns. According to the definitions above, the supplier profit generated from the selling period $\left[z_{j-1}, z_{j}\right]$ is the revenue-sharing revenue minus the relevant costs which include the variable production cost, holding cost, deteriorating cost and shortage cost:

$$
\pi_{\text {cons }, S}(p, \xi)=(1-v) p \int_{z_{j-1}}^{z_{j}} D(p, t) d t-
$$

$$
\begin{array}{r}
c\left(\int_{z_{j-1}}^{\xi} D(p, t) e^{\varphi\left(t-z_{j-1}\right)} d t+\int_{\xi}^{z_{j}} D(p, t) d t\right) \\
-\int_{z_{j-1}}^{\xi} h\left(\int_{z_{j-1}}^{t} e^{\varphi(t-u)} d u\right) D(p, t) d t-\int_{\xi}^{z_{j}} s\left(z_{j}-t\right) D(p, t) d t .
\end{array}
$$

The sequence of events for consignment model is as follows: both companies negotiate a revenue-sharing allocation $v$ beforehand, based on which the supplier determines the coordinated retail price and depletion time simultaneously over given $z_{j-1}$ and $z_{j}$ for the supply chain. Therefore, the optimal retail price and depletion time, that maximizes the supplier profit over period $\left[z_{j-1}, z_{j}\right]$ in the consignment contract can be obtained by taking the first-order derivative of Eqn. (4) with respect to $p$ and $v$ separately and setting the results equal to zero. The optimal replenishment scheduling, and the associated retail price and depletion time for the multi-period planning horizon formulation can be obtained by dynamic programming approach.

\section{Conclusion}

This work conducted the experiments to attend qualitative insights into the structures of the proposed contracts. The two contracts in this work, incorporating the proposed solution procedures, were implemented on a personal computer. Table 1 lists numerical results generated by the two contracts, including the replenishment number, optimal retail price, lot-size, retailer profit, supplier profit and channel profit.

This investigation deals with the emerging research on managing a vertically decentralized single-supplier and single-retailer multi-period channel which produces and sells deteriorating goods with no consideration of fixed costs in a marketplace. This study formulated two decision models for the decentralized channel under price-only contract and consignment contract respectively. A numerical study is conducted to clarify the benefits of the proposed consignment contract that can increase channel-wide profit for the vertically decentralized channel. The proposed model based on a periodic review policy can be used as an add-on optimizer, which makes it applicable to the channel-wide profit maximization between production and marketing planning in a vertical supply chain.

Table 1. Numerical results.

\begin{tabular}{lcccccc}
\hline Contracts & $\boldsymbol{n}$ & $p$ & $Q$ & $\Pi_{\boldsymbol{R}}$ & $\Pi_{\boldsymbol{S}}$ & $\Pi_{C}$ \\
\hline $\begin{array}{l}\text { Price-only contract } \\
\text { Consignment }\end{array}$ & 6 & 14.5893 & 1173 & 9989 & 4283 & 14272 \\
contract & 6 & 13.1132 & 1357 & 8052 & 6685 & 14736 \\
\hline
\end{tabular}




\section{Acknowledgements}

The author would like to thank the Ministry of Science and Technology (Taiwan) for the partial support of this study under Contract No. MOST 104-2410-H-153-012-MY2.

\section{References}

[1] Tsay AA, Nahmias S, Agrawal N. Modeling supply chain contracts: a review. In S. Tayur, R. Ganeshan and M. Magazine (eds), Quantitative Models for Supply Chain Management, Kluwer Academic Publishers, Boston. 1999.

[2] Cachon GP. Supply chain coordination with contracts. In A. G de Kok and S. Graves (eds), Handbooks in Operations Research and Management Science: Supply Chain Management, Elsevier Science Publishers B.V. (North Holland), Amsterdam. 2003.

[3] Höhn MI. Relational supply contracts: optimal concessions in return policies for continuous quality improvements. Lecture Notes in Economics and Mathematical Systems 2010; 629:1-119.

[4] Panda S, Modak, NM, Pradhan, D. Corporate social responsibility, channel coordination and profit division in a two-echelon supply chain. International Journal of Management Science and Engineering Management 2016; 11(1): 22-33.

[5] Modak NM, Panda S, Sana SS. Pricing policy and coordination for a distribution channel with manufacturer suggested retail price. International Journal of Systems Science: Operations \& Logistics 2016; 3(2): 92-101.

[6] Chena X, Wangb X, Chan HK. Channel coordination through subsidy contract design in the mobile phone industry. International Journal of Production Economics 2016; 171: 97-104.

[7] Bolen WH. Contemporary Retailing, third ed. Prentice Hall: New Jersey. 1988.

[8] Ha AY, Tong S. Revenue sharing contracts in a supply chain with uncontractible actions. Naval Research Logistics 2008; 55(5): 419-431.

[9] Ru J, Wang Y. Consignment contracting: who should control inventory in the supply chain. European Journal of Operational Research 2010; 201(3):760-769.
[10] Chen LT. Dynamic supply chain coordination under consignment and vendor-managed inventory in retailer-centric B2B electronic markets. Industrial Marketing Management 2013; 42(4):518-531.

[11] Chen LT. Buyer-supplier relationship and optimisation model in a dynamic collaborative network with shortages allowed. International Journal of Computer Integrated Manufacturing 2017; 30(7):755-767.

[12] Simchi-Levi D, Kaminsky P, Simchi-Levi E. Designing and Managing the Supply Chain: Concepts, Strategies, and Case Studies. McGraw-Hill: Taiwan, 2008.

[13] Pashigian BP, Bowen B. Why are products sold on sale? explanations of pricing regularities. The Quarterly Journal of Economics 1991; 106:1015-1038.

[14] Elmaghraby W, Keskinocak P. Dynamic pricing in the presence of inventory considerations: research overview, current practices, and future directions. Management Science 2003; 49:1287-1309.

[15] Chen JM, Chen LT. Market-driven production lot-size and scheduling with finite capacity for a deteriorating item. Production Planning and Control 2006; 17(1):44-53.

[16] Cabral L. Dynamic pricing in customer markets with switching costs. Review of Economic Dynamics 2016; 20:43-62.

[17] Varella RR, J Frazão, Oliveira AVM. Dynamic pricing and market segmentation responses to low-cost carrier entry. Transportation Research Part E: Logistics and Transportation Review 2017; 98: 151-170.

[18] Newton FJ. Information please: do you have any information on inventory shortages? Management Accounting 1988; 70:52-53.

[19] Wee HM, Jong JF, Yang PC. A discussion on economic ordering policy of deteriorated item for vendor and buyer. Production Planning \& Control 2006; 17(8):792-795.

[20] Lin YS, Yu JCP, Wang KJ. An efficient replenishment model of deteriorating items for a supplier-buyer partnership in hi-tech industry. Production Planning \& Control 2009; 20(5): 431-444. 